\title{
Lactic dehydrogenase as a biochemical marker of adverse pregnancy outcome in severe pre-eclampsia, Gujarat
}

\author{
Rohit Jain, Chintan Upadhyay*, Latika Mehta, Bipin Nayak, Gaurav Desai
}

Department of Obstetrics and Gynecology, GMERS Medical College, Gandhinagar, Gujarat, India

Received: 18 May 2017

Revised: 15 June 2017

Accepted: 20 June 2017

\author{
*Correspondence: \\ Dr. Chintan Upadhyay, \\ E-mail: drchintan1508@gmail.com
}

Copyright: (c) the author(s), publisher and licensee Medip Academy. This is an open-access article distributed under the terms of the Creative Commons Attribution Non-Commercial License, which permits unrestricted non-commercial use, distribution, and reproduction in any medium, provided the original work is properly cited.

\begin{abstract}
Background: Serum LDH levels can be used to assess the extent of cellular death and thereby the severity of disease in this group of women. This will help in making decision, about the management guidelines to the better the maternal and fetal outcome. Objective of present study was compare serum LDH levels in the normal pregnant women and in women with preeclampsia and eclampsia in ante-partum period and to study the association of maternal and perinatal outcomes with serum LDH levels.

Methods: It is a prospective study done at Obstetrics and Gynecology department, GMERS medical college and civil hospital, Gandhinagar during August-September 2016. Participants were divided into four groups according to severity of disease and into three groups according to serum LDH level.

Results: Mean level of LDH (IU/l) in Control, Mild pre-eclampsia, Severe pre-eclampsia \& Eclampsia was 302.33, $398.56,675.26 \& 1589.85$ respectively. Out of total 34 cases with $\mathrm{LDH}$ level $>800 \mathrm{IU} / \mathrm{L}, 47.1 \%$ cases had $\geq 160 \mathrm{~mm}$ hg SBP \& $52.9 \%$ had $\geq 110 \mathrm{~mm}$ hg DBP, mean gestational age and mean baby weight was 36.88 week and $1950 \mathrm{gm}$, mean apgar score at 10 min was $6.96,47.1 \%$ had uneventful outcome, whereas $58.8 \%$ had neonatal complications and $5.9 \%$ had neonatal death. Almost $26.5 \%$ still births, $47.1 \%$ perinatal deaths.

Conclusions: Higher serum LDH levels during pregnancy have significant association with severity of disease and maternal and fetal outcomes in patients of preeclampsia and eclampsia and can be considered as a supportive prognostic tool from early third trimester.
\end{abstract}

Keywords: Apgar score, Birth weight, Diastolic BP, Gestational age, Perinatal complications, Systolic BP

\section{INTRODUCTION}

Preeclampsia, concern with high blood pressure (BP $\geq 140 / 90 \mathrm{mmHg}$ ) and increased mother's urinary protein (urinary albumin protein $\geq 300 \mathrm{mg} / 24 \mathrm{~h}$ ) is a dangerous complication of pregnancy, condition that typically begins after 20th week of pregnancy. ${ }^{1,2}$

Pre-eclampsia is ranging from mild to severe form and is a reason of maternal and neonatal mortality and morbidity. ${ }^{3,4}$ Prevalence of pre-eclampsia in World, India and Gujarat was $4.0 \%, 8 \%$ to $10 \%$ and $35.3 \%$ respectively. These are multisystem disorders and lead to a lot of cellular death. ${ }^{4-6}$

Level of intra-cellular Lactate Dehydrogenase (LDH) increased in the women due to pre-eclampsia because of cellular death. So, serum LDH levels can be used to assess the extent of cellular death and thereby the severity of disease in this group of women. This will help in making decision, about the management guidelines for better maternal and fetal outcome. ${ }^{7}$ Objectives of present 
study were to compare serum LDH levels in the normal pregnant women and in women with preeclampsia and eclampsia in ante-partum period and to study the association of maternal and perinatal outcomes with serum LDH levels.

\section{METHODS}

This was a prospective study done at Obstetrics and Gynecology department, GMERS medical college and civil hospital, Gandhinagar during August-September 2016 after taking permission from Institutional Ethical Committee (IEC) of GMERS Medical College, Gandhinagar. Study enrolled 102 pregnant women who attended OPD at Obstetrics and Gynecology department after obtaining written consent.

A sample size of 102 is obtained by using the hypothesis testing method and based on following assumptions: $95 \%$ confidence intervals, prevalence of pre-eclampsia in Gujarat6 $35.3 \%$ and $5 \%$ margin of error. The calculated minimum sample has been inflated by $10 \%$ to account for anticipated subject non response.

Present study was enrolled women in third trimester of pregnancy and divided them into four groups.

- Group 1 Third trimester healthy pregnant women $(\mathrm{n}=$ 28)

- Group 2 Third trimester pregnant women who has mild pre-eclampsia $(n=30)$

- Group 3 Third trimester pregnant women who has severe pre-eclampsia $(\mathrm{n}=22)$

- Group 4 Third trimester pregnant women who has eclampsia $(n=22)$

Participants was also divided according to the serum LDH level into following groups:
- $\mathrm{A}<600 \mathrm{IU} / \mathrm{L}$

- B 600-800 IU/1

- $\mathrm{C}>800 \mathrm{IU} / \mathrm{L}$

Exclusion Criteria of present study was mothers with hypertension with $<20$ weeks gestation; Preexisting diabetes mellitus, renal disease, liver disorder, thyroid disorder, epilepsy.

Outcome of the study was LDH level, Gestational age, baby weight, APGAR score, Maternal complication (eclampsia, abruptio placenta, intracranial heamorrhage etc.) neonatal complications, neonatal death, still birth, perinatal death, maternal vitals.

\section{Variable}

- $\quad$ Mild pre-eclampsia: Onset of hypertension after 20 weeks of gestation with diastolic blood pressure (DBP) $>90$ and $\leq 110 \mathrm{mmHg}$ with or without proteinuria.

- Severe pre-eclampsia: DBP >110 mmHg was measured on two occasions 6 hours apart with significant proteinuria (>500 mg/24 h).

\section{RESULTS}

Around $27.4 \%$ pregnant women have normal blood pressure. Almost 29.4\%, 21.6\% and $21.6 \%$ cases were belonged to mild pre-eclampsia, severe pre-eclampsia and eclampsia category respectively.

All the participants of were belonged to the age group of 21-30 year but the difference between mean age among all category was statistically not significant $(p>0.05)$. Distribution according to parity was similar in both groups and also statistically significant $(\mathrm{p}<0.05)$ (Table 1).

Table 1: Distribution of patients with age and parity.

\begin{tabular}{|llllll|}
\hline Group & Control & Mild pre-eclampsia & Severe pre-eclampsia & Eclampsia & P value \\
\hline No. & $28(27.4 \%)$ & $30(29.4 \%)$ & $22(21.6 \%)$ & $22(21.6 \%)$ & \\
\hline Age (mean \pm SD) & $26.7 \pm 3.7$ & $25.5 \pm 4.2$ & $24.9 \pm 3.3$ & $25.4 \pm 3.8$ & $0.875^{*}$ \\
\hline Parity 0 (no.) & 13 & 16 & 14 & 13 & $0.04 *$ \\
\hline
\end{tabular}

Table 2: Association of systolic and diastolic BP with LDH levels in various groups.

\begin{tabular}{|c|c|c|c|c|}
\hline Group & LDH level (IU/I) (mean+SD) & Range & F & $\mathbf{P}$ \\
\hline Control & $302.33 \pm 92.48$ & $95-488$ & \multirow{5}{*}{14.85} & \multirow{5}{*}{$<0.001^{*}$} \\
\hline Mild pre-eclampsia & $398.56 \pm 158.23$ & $88-695$ & & \\
\hline Severe pre-eclampsia & $675.26 \pm 388.58$ & 199-1759 & & \\
\hline Eclampsia & $1589.85 \pm 1856.32$ & $226-8832$ & & \\
\hline Total & $968.99 \pm 1345.39$ & $199-8585$ & & \\
\hline
\end{tabular}

* One way Analysis of Variance (ANOVA) 
Table 2 show that Mean level of LDH (IU/l) in Control, Mild pre-eclampsia, Severe pre-eclampsia and Eclampsia was $302.33,398.56,675.26$ and 1589.85 respectively.

Table 3 show that out of total 57 cases with LDH level $<600 \mathrm{IU} / 1,17.6 \%$ had normal SBP, 57.9\% had $140<160$ $\mathrm{mm}$ hg SBP and $24.5 \%$ had $\geq 160 \mathrm{~mm}$ hg SBP and $14.1 \%$ had $\geq 110 \mathrm{~mm}$ hg DBP. Out of total 11 cases with LDH level $600-800 \mathrm{IU} / 1,45.4 \%$ participants had $\geq 160 \mathrm{~mm} \mathrm{hg}$ SBP and $27.3 \%$ had $\geq 110 \mathrm{~mm}$ hg DBP and out of total 34 cases with $\mathrm{LDH}$ level $>800 \mathrm{IU} / \mathrm{L}, 47.1 \%$ cases had $\geq 160$ $\mathrm{mm}$ hg SBP and $52.9 \%$ had $\geq 110 \mathrm{~mm} \mathrm{hg} \mathrm{DBP}$. Difference between DBP and SBP of all groups was statistically significant $(\mathrm{p}<0.05)$.

Table 3: Association of systolic and diastolic BP with LDH levels in various groups.

\begin{tabular}{|c|c|c|c|c|c|}
\hline \multirow{2}{*}{ Groups } & \multicolumn{3}{|c|}{ LDH level (IU/I) } & \multirow{2}{*}{ Total } & \multirow{2}{*}{ P value } \\
\hline & $<600(n=57)$ & $600-800(n=11)$ & $>800(n=34)$ & & \\
\hline \multicolumn{6}{|c|}{ Diastolic BP (mmhg) } \\
\hline $60-<90$ & $4(7.0)$ & $0(0.0)$ & $2(5.9)$ & $6(5.9)$ & \multirow{3}{*}{$<0.01 *$} \\
\hline $90-<110$ & $45(78.9)$ & $8(72.7)$ & $14(41.2)$ & $67(65.7)$ & \\
\hline$\geq 110$ & $8(14.1)$ & $3(27.3)$ & $18(52.9)$ & $29(28.4)$ & \\
\hline \multicolumn{5}{|c|}{ Systolic BP (mmhg) } & \multirow{4}{*}{$<0.05^{*}$} \\
\hline $90-<140$ & $10(17.6)$ & $3(27.3)$ & $3(8.8)$ & $16(15.7)$ & \\
\hline $140-<160$ & $33(57.9)$ & $3(27.3)$ & $15(44.1)$ & $51(50.0)$ & \\
\hline$\geq 160$ & $14(24.5)$ & $5(45.4)$ & $16(47.1)$ & $35(34.3)$ & \\
\hline
\end{tabular}

Table 4: Comparison of LDH level with perinatal outcome.

\begin{tabular}{|c|c|c|c|c|}
\hline \multirow{2}{*}{ Parameters } & \multicolumn{3}{|l|}{ LDH Level } & \multirow{2}{*}{$P$ value } \\
\hline & $<600(\mathrm{n}=57)$ & $600-800(n=11)$ & $>800(n=34)$ & \\
\hline $\begin{array}{l}\text { Mean gestational age } \\
(\text { Mean } \pm \text { SD) (in week) }\end{array}$ & $37.02 \pm 2.88$ & $35.26 \pm 2.68$ & $36.88 \pm 4.57$ & $<0.05^{*}$ \\
\hline $\begin{array}{l}\text { Mean baby weight } \\
\text { (Mean } \pm \text { SD) (in gm) }\end{array}$ & $2490 \pm 698$ & $1893 \pm 583$ & $1950 \pm 182$ & $<0.001 *$ \\
\hline \multicolumn{5}{|l|}{ Apgar Score } \\
\hline At $1 \mathrm{~min}$ & $6.15 \pm 1.01$ & $6.85 \pm 0.82$ & $4.52 \pm 1.27$ & $<0.01 *$ \\
\hline At $5 \mathrm{~min}$ & $6.98 \pm 1.02$ & $7.12 \pm 0.67$ & $6.12 \pm 1.56$ & $<0.05^{*}$ \\
\hline At $10 \mathrm{~min}$ & $7.97 \pm 0.69$ & $7.89 \pm 1.25$ & $6.96 \pm 1.73$ & $<0.01 *$ \\
\hline \multicolumn{5}{|l|}{ Outcome } \\
\hline Alive & $48(84.2)$ & $6(54.5)$ & $16(47.1)$ & \multirow{5}{*}{$<0.001 * *$} \\
\hline Neonatal complications & $13(22.8)$ & $4(36.4)$ & $20(58.8)$ & \\
\hline Neonatal death & $1(1.8)$ & $5(45.5)$ & $4(11.8)$ & \\
\hline Still birth & $2(3.6)$ & $3(27.3)$ & $9(26.5)$ & \\
\hline Perinatal deaths & $12(21.1)$ & $6(54.5)$ & $16(47.1)$ & \\
\hline
\end{tabular}

*One way Analysis of Variance (ANOVA), **Chi-square Test

Mean gestational age and mean baby weight was 37.02 week and $2490 \mathrm{gm}$ in cases with LDH level <600 IU/l, 35.26 week and $1893 \mathrm{gm}$ in cases with LDH level 600$800 \mathrm{IU} / \mathrm{l}, 36.88$ week and $1950 \mathrm{gm}$ in cases with LDH level >800 IU/l respectively and difference in mean gestational age and mean baby weight was statistically significant $(\mathrm{p}<0.05)($ Table 4$)$.

Mean apgar score at 1 min was 6.15 in cases with LDH level <600 IU/1, 6.85 in cases with LDH level 600-800 IU/1, 4.52 in cases with LDH level >800 IU/1 respectively. Mean apgar score at 10 min was 7.97 in cases with LDH level <600 IU/l, 7.89 in cases with LDH level 600-800 IU/1, 6.96 in cases with LDH level >800
IU/1 respectively. Difference in mean apgar score at 1,5 and 10 minutes among all groups was statistically significant $(\mathrm{p}<0.05)$ (Table 4).

When LDH levels were normal (57 cases), 84.2\% cases had an uneventful perinatal period. $22.8 \%$ had neonatal complications, while $5.3 \%$ neonatal deaths were reported and there were two cases $(3.6 \%)$ of still births, i.e., there were $21.1 \%$ perinatal deaths.

In the women with LDH levels in the range of 600-800 IU/1 (11 cases), 54.5\% had uneventful outcome, while $45.5 \%$ had neonatal death and $36.4 \%$ had neonatal complications. In this group $27.3 \%$ still births were 
present i.e., there were $54.5 \%$ perinatal deaths. In the third group where LDH levels were more elevated there were 34 cases out of which only $47.1 \%$ had uneventful outcome, whereas $58.8 \%$ had neonatal complications and $5.9 \%$ had neonatal death. Almost $26.5 \%$ still births were reported, i.e., there were $47.1 \%$ perinatal deaths. And the occurrence of different perinatal outcomes among all groups was statistically significance $(\mathrm{p}<0.05)$ (Table 4$)$.

\section{DISCUSSION}

Preeclampsia is an idiopathic multisystem disorder, that is specific to human pregnancy and the prevention of it major impact on decreasing maternal and perinatal morbidity and mortality.

Present study, LDH has been evaluated as a biochemical marker for the prediction of complications of preeclampsia and eclampsia.

In present study, all the participants were belonged to younger age group $(\mathrm{p}<0.05)$ and most of were nalliparous $(\mathrm{p}<0.05)$. Similar finding was observed in study done by Jaiswar SP et al, Qublan et al, Kantipudi UD et al, and Umasatyasri Y et al. ${ }^{7-10}$

Mean LDH level of all patients of study was 968.99 IU/1 with 1345.39 SD. Mean level of LDH was almost double in patients of Sever pre-eclampsia and much higher in patients of eclampsia group in comparison to group of cases with normal LDH level $(\mathrm{p}<0.05)$. This finding is comparable with study done by Julie Samarth et al, Liggy A et al, Malvino et al [5 disccusion mathi], Jaiswar SP et al, Qublan et al and Umasatyasri Y et al. ${ }^{8,10-12}$

Present study observed stage 2 HTN [JNC classification] was found in cases with LDH level more than $800 \mathrm{IU} / 1$ $(p<0.05)$. This finding is comparable with study done by Jaiswar SP et al, Qublan et al, Kantipudi UD et al, and Umasatyasri $\mathrm{Y}$ et al. ${ }^{7-10}$ In the present study the LDH levels were significantly raised with the severity of the disease $(\mathrm{P}<0.001)$ and this was in accordance with the study done by Jaiswar SP et al, Qublan et al and Liggy A et al. ${ }^{7,8,11}$

The mean gestational age at the time of delivery in the present study was significantly less in patients with increasing $\mathrm{LDH}$ levels $(\mathrm{P}<0.05)$. This indicates increase in preterm deliveries in patients with higher LDH levels. This finding is comparable with study done by Jaiswar SP et al, Qublan et al, Umasatyasri Y et al and Liggy A et al. ${ }^{7,8,10,11}$ The mean Apgar scores were significantly reduced at $1 \mathrm{~min}$ and $5 \mathrm{~min}$, in the present study, showing mild to severe depression of the newborn baby with increasing LDH levels $(\mathrm{p}<0.05)$ for Apgar score at 1 and 5 min respectively.

Regarding perinatal outcome, present study observed that Neonatal complications, Neonatal Death Still Birth, Perinatal Deaths were increased with increasing level of
LDH level. These outcomes were significantly higher among cases with LDH level >800 IU/1 in comparison with cases with LDH level $<600$ IU/1 $(p<0.05)$. Similar finding was observed in study done by Jaiswar SP et al, Qublan et al, Kantipudi UD et al, and Umasatyasri Y et al. ${ }^{7-10}$

\section{CONCLUSION}

Higher serum LDH levels during pregnancy have significant association with severity of disease and maternal and fetal outcomes in patients of preeclampsia and eclampsia and can be considered as a supportive prognostic tool from early third trimester.

\section{Funding: No funding sources}

Conflict of interest: None declared

Ethical approval: The study was approved by the Institutional Ethics Committee

\section{REFERENCES}

1. Roberts JM, Lain KY. Recent Insights into the pathogenesis of preeclampsia. Placenta. 2002;23:359-372.

2. Agrawal S, Walia GK. Prevalence and Risk Factors for Symptoms Suggestive of Pre-Eclampsia in Indian Women. J Womens Health Issues Care. 2014;3:6.

3. Duley L. The global impact of pre-eclampsia and eclampsia. Semin Perinatol. 2009;33:130-7.

4. Yuan T, Wang W, Li XL, Li CF, Li C, Gou WL. Clinical characteristics of fetal and neonatal outcomes in twin pregnancy with preeclampsia in a retrospective case-control study. Medicine. 2016;95:43.

5. Sajitha M, Nimbargi V, Modi A, Sumariya R, Pawar A. Incidence of pregnancy induced hypertension and prescription pattern of antihypertensive drugs in pregnancy. Int J Pharma Sci Res. 2014;5(4):163-170.

6. Agrawal S, Walia GK. Prevalence and risk factor for symptoms suggestive of pre-eclampsia in Indian women. J Women's Health. 2014;3(6):2-9.

7. Jaiswar SP, Gupta A, Sachan R, Natu SN, Shaili M. Lactic -Dehydrogenase: A biochemical marker for preeclampsia-eclampsia. JOGI. 2011;61(6):645-8.

8. Qublan HS, Amarun V, Bateinen O. LDH as biochemical marker of adverse pregnancy outcome in severe preeclampsia. Med Sci Monit. 2005;11:393-7.

9. Kantipudi UD, Sheela SR, Dayanand CD, Sivaraj N. Relationship of serum leptin, lactate dehydrogenase levels and severity in preeclampsia. South Am J Academic Res. 2016;1-8.

10. Umasatyasri Y, Vani I, Shamita P. Role of LDH (Lactate dehydrogenase) in preeclampsia marker: An observational study. IAIM. 2015;2(9):88-93.

11. Andrews L, Patel N. Correlation of serum lactate dehydrogenase and pregnancy induced hypertension with its adverse outcomes. Int $\mathrm{J}$ Res Med Sci. 2016;4:1347-50. 
12. Malvino E, Munoz M, Ceccotti C, Janello G, McLounghlin D, Pawlak P et al. Maternal morbidity and perinatal mortality in HELLP syndrome, multicentric studies in intensive care units Buenos Aires area. Medicina (B. Aires). 2005;65(1):17-23.
Cite this article as: Jain R, Upadhyay C, Mehta L, Nayak B, Desai G. Lactic dehydrogenase as a biochemical marker of adverse pregnancy outcome in severe pre-eclampsia, Gujarat. Int J Reprod Contracept Obstet Gynecol 2017;6:3418-22. 